\title{
COMPARAÇÃO DE DIFERENTES ESTRATÉGIAS DE PROGRAMAÇÃO DE IRRIGAÇÃO SUPLEMENTAR EM MILHO
}

\author{
MORETHSON RESENDE ${ }^{1} \&$ ANTÔNIO CARLOS OLIVEIRA ${ }^{1}$
}

\begin{abstract}
${ }^{1}$ Embrapa milho e Sorgo. Rodovia 424, km 45 - cx. postal 151 - CEP 35701 - Sete Lagoas, MG. Email: resende@cnpms.embrapa.br; oliveira@cnpms.embrapa.br
\end{abstract}

Revista Brasileira de Milho e Sorgo, v.4, n.2, p.205-214, 2005

\begin{abstract}
RESUMO - Uma das estratégias mais simples, embora pouco precisa, para programar irrigações é utilizar a média da evapotranspiração de referência (ETo), de uma série histórica de dados climáticos e através do método de balanço de água no solo. Com isso, é possível gerar um calendário de irrigações, com as respectivas datas e lâminas de água a serem aplicadas durante o ciclo da cultura. Desenvolveu-se um trabalho, com a cooperação da UFMG, com o objetivo de aumentar a precisão desse método, utilizando-se Redes Neurais Artificiais (RNAs) para ajustar e predizer a ETo diária, com base em uma série histórica de dados climáticos. Um experimento foi conduzido em duas épocas de plantio (27 de janeiro de 2003 e 02 de setembro de 2003), para testar a precisão desse método em relação ao uso da média de ETo, da ETo predita por RNAs sem ajuste, da ETo calculada diariamente e da evaporação da água do tanque Classe A (ECA), através do balanço de água no solo e do uso de tensiômetros. O manejo das irrigações pelo balanço de água no solo, utilizando-se a ETo estimada diariamente pelo método de Penman-Monteith, considerado como padrão, utilizando-se dados de ETo ajustados e preditos por RNAs e utilizando-se a ECA, proporcionou as maiores produtividades de milho em ambos os experimentos. O manejo utilizando-se valores médios de ETo e valores de ETo preditos e não ajustados de uma série histórica de dados climáticos causou redução de produtividades de milho, em relação ao padrão.
\end{abstract}

Palavras-chave - manejo de irrigação, redes neurais, evapotranspiração, cultura do milho.

\section{COMPARISON OF DIFFERENT IRRIGATION SCHEDULING STRATEGIES ON MAIZE}

\begin{abstract}
Although it lacks precision, one of the most simple strategies for irrigation scheduling is the reference evapotranspiration average(ETo), estimated from historical climate data and through the soil water budget method. This permits a prediction of time and amount of water to be applied during the crop cycle. In cooperation with UFMG a work was carried out to increase the precision of this method by using Neural Artificial Network (NAN) to adjust and predict daily ETo from a historical climate data base. An experiment was conducted with two planting dates, (01/27/2003 and 09/02/2003) in order to test the precision of this method in relation to the daily estimated ETo (standard), the average ETo, the predicted ETo by using NAN without adjustment and ETo estimated by Evaporation of a Class A pan (ECA), using soil water balance in all ETo alternatives. The daily estimated ETo (standard), ajusted and predicted daily ETo and ETo estimated by ECA, brought the highest productivity. The irrigation scheduling using average ETo
\end{abstract}


and one that used predicted ETo by using NAN without adjustment caused reduction in the productivity when compared with the standard treatment.

Key words: irrigation scheduling, neural network, evapotranspiration, maize crop

A irrigação comporta-se como uma ciência exata até que a água seja derivada do canal ou sai do aspersor ou gotejador. Após a infiltração da água no solo, para posterior absorção pelas raízes e transpiração pelas plantas, vários termos e expressões são utilizados para tentar explicar um sistema extremamente complexo, que envolve os diferentes tipos de solo, de clima e de planta. Há inúmeras propostas de equipamentos e formas de medir e estimar o conteúdo de água no solo e na planta, o que atesta a inexistência de um procedimento de aceitação geral sobre uma forma precisa de programa as irrigações, ao longo do ciclo das culturas.

Após a implantação de um projeto de irrigação, o produtor necessita ser orientado quanto à programação de suas irrigações, para que ele possa obter o máximo rendimento da atividade agrícola com mínima degradação ambiental. Isso, normalmente, não tem acontecido.

Em 1993, a CEMIG, em convênio com a Universidade Federal de Viçosa, desenvolveu um projeto de otimização de energia e concluiu que as perdas de água, em onze pivôs avaliados, chegaram a 17,8\% (CEMIG, 1993). Em trabalho semelhante, em aspersão convencional, com 257 irrigantes, concluiu-se que as irrigações eram deficientes em $75 \%$ das propriedades, foram adequadas em $12,5 \%$ e foram em excesso em $12,5 \%$. Concluiu-se ainda que, em 50\% dos casos, as irrigações foram feitas antes da hora recomendada, em $37,5 \%$ foram realizadas no momento certo e em $12,5 \%$ das propriedades as irrigações foram realizadas tardiamente (CEMIG, 1996).

A sustentabilidade das áreas irrigadas, a incorporação e a conseqüente expansão de novas áreas devem estar associadas ao aumento de produtividade e à preservação dos recursos naturais. Há indicações de que $63 \%$ dos lotes em sistemas de irrigação no norte do Estado de Minas Gerais estavam aplicando excesso de água e que as dotações de irrigação eram constantes e iguais às determinadas no projeto para o ano todo e às vezes superiores às requeridas nos meses de maior demanda evaporativa (Almeida, 1997). Estima-se que, em média, a eficiência de irrigação, no mundo, é de $45 \%$ e as maiores perdas são devido ao inadequado manejo de irrigação (Christofidis, 1999). Quando se procura racionalizar o uso da água e preservar o meio ambiente, é de fundamental importância estimar com certo grau de precisão o quanto e quando irrigar.

Considerando-se os altos custos e a deficiência generalizada de equipamentos de controle das condições de umidade do solo, fatores da planta e atmosfera, o método do balanço de água no solo constitui uma estratégia viável de se programar as irrigações (Steele et al., 2000), utilizando-se dados das características físicas do solo e do requerimento diário de água pela cultura, que pode ser determinado pela estimativa da evapotranspiração de referência (ETo), pelo método de Penman-Monteith (Allen et al., 1998), que é reconhecido internacionalmente como um dos mais precisos (Jensen et al., 1990 Kumar et al., 2002) e pelo coeficiente da cultura (Kc) (Doorenbos \& Pruitt, 1976). A programação de irrigação utilizando o método do balaço de água no solo é feita determinando-se a ETo diariamente, o que, além de trabalhoso, necessita da coleta diária de dados climáticos. Esse mesmo método também vem sendo usado, utilizando-se 
valores médios de ETo diários de uma série histórica de dados climáticos, para prever futuras irrigações. Essa estratégia, embora muito simples de ser utilizada, não é recomendável em condições de alta variabilidade das variáveis climáticas (Smith et al., 1985 e Resende et al., 2002). Visando melhorar a precisão, foi desenvolvido o Método Resende (Resende, 2004) para se programar as irrigações, através do ajuste dos valores de ETo para os dias chuvosos de uma série histórica de dados climáticos e a predição de valores futuros de ETo (Resende et al., 2000, 2002, 2003), utilizando-se Redes Neurais Artificiais (RNAs), através da metodologia desenvolvida por Souza et al. (2002). As RNAs vem sendo largamente utilizadas em diversos trabalhos ligados a modelos envolvendo o tema água (Kumar et al., 2002).

O objetivo deste trabalho foi comparar, em condições de campo, vários métodos recomendados para manejar irrigações na cultura do milho com o método desenvolvido por Resende et al. (2002).

\section{Material e Métodos}

Os experimentos foram conduzidos em duas épocas de plantio: 27 de janeiro de 2003 e 02 de setembro de 2003, na área experimental da Embrapa Milho e Sorgo, em Sete Lagoas-MG em um solo classificado como latossolo vermelho de textura argilosa, cujas características físicas e químicas são apresentadas na Tabela 1.

TABELA 1. Características físicas e químicas do solo da área experimental

\begin{tabular}{lccc}
\hline \multirow{2}{*}{ Discriminação } & \multirow{2}{*}{ Unidade } & \multicolumn{2}{c}{ Valor/profundidade do solo (cm) } \\
\cline { 3 - 4 } & & $\mathbf{0 - 2 0}$ & $\mathbf{2 0} \mathbf{- 4 0}$ \\
\hline $\mathbf{A}-$ Química & - & 5,7 & 5,4 \\
$\mathrm{pH}$ em $\mathrm{H}_{2} \mathrm{O}$ & $\mathrm{cmolc} / \mathrm{dm}^{3}$ & 3,78 & 4,41 \\
$\mathrm{H}+\mathrm{Al}$ & $\mathrm{cmolc} / \mathrm{dm}^{3}$ & 4,23 & 2,11 \\
$\mathrm{Ca}$ & $\mathrm{cmolc} / \mathrm{dm}^{3}$ & 0,43 & 0,21 \\
$\mathrm{Mg}$ & $\mathrm{mg} / \mathrm{dm}^{3}$ & 31 & 11 \\
$\mathrm{~K}$ & $\mathrm{cmolc} / \mathrm{dm}^{3}$ & 14 & 4 \\
$\mathrm{P}$ & $\mathrm{dag} / \mathrm{kg}$ & 2,92 & 2,39 \\
$\mathrm{M} . \mathrm{O}$. & & & \\
& & 5 & 5 \\
B - Física & $\%$ & 5 & 5 \\
Areia grossa & $\%$ & 26 & 21 \\
Areia fina & $\%$ & 64 & 69 \\
Silte & $\%$ & 1,06 & 0,96 \\
Argila & $\mathrm{g} / \mathrm{cm}^{3}$ & 36,15 & 33,80 \\
Densidade aparente & $\mathrm{Vol} \%$ & 34,66 & 31,63 \\
Conteúdo de água a $10 \mathrm{kPa}$ & $\mathrm{Vol} \%$ & 24,21 & 25,58 \\
Conteúdo de água a $70 \mathrm{kPa}$ & $\mathrm{Vol} \%$ & & \\
Conteúdo de água a $1500 \mathrm{kPa}$ & &
\end{tabular}


No plantio de janeiro, em sistema de plantio direto, utilizou-se o milho híbrido simples BRS1010. A adubação de plantio foi feita com $400 \mathrm{~kg} \mathrm{ha}^{-1}$ de $08-28-16+\mathrm{Zn}$ e a de cobertura, com $110 \mathrm{~kg} \mathrm{ha}^{-1}$ de N, na forma de uréia. No plantio de setembro, também em sistema de plantio direto, utilizou-se o mesmo híbrido simples BRS1010. A adubação de plantio foi feita com $300 \mathrm{~kg} \mathrm{ha}^{-1}$ de $08-28-16+\mathrm{Zn}$ e a de cobertura, com $120 \mathrm{~kg} \mathrm{ha}^{-1}$ de $\mathrm{N}$, na forma de sulfato de amônio. Em ambos os experimentos, foram utilizados herbicidas e inseticidas para o controle de plantas daninhas e da lagarta-do-cartucho, respectivamente.

O delineamento experimental dos dois experimento foi o de blocos casualizados, com três repetições e seis tratamentos. Nos cinco primeiros tratamentos, as irrigações foram feitas segundo o método do balanço de água no solo, utilizando-se dados da caracterização física do solo (Tabela 1) e dados de evapotranspiração de referência (ETo) de uma série histórica de dados climáticos (de 1958 a 2003) e de evaporação (E) diária de Sete Lagoas, MG, (Tabela 2). Nesses tratamentos, o momento de efetuar as irrigações foi estimado quando as lâminas de água armazenadas até $40 \mathrm{~cm}$ de profundidade do solo, entre 10 e $70 \mathrm{kPa}$, foram consumidas pela evapotranspiração da cultura, segundo o balanço de água no solo. O último tratamento, T6, foi irrigado toda vez que a média das leituras de três tensiômetros, instalados a $20 \mathrm{~cm}$ de profundidade, indicavam tensões entre 60 e $70 \mathrm{kPa}$.

TABELA 2. Resumo dos tratamentos

\section{Tratamentos}

$\mathrm{T} 1 *$

Uso dos valores ETo ajustada e preditos, utilizando série histórica de dados

$\mathrm{T} 2 *$

Uso dos valores ETo média, utilizando série histórica de dados

$\mathrm{T} 3 *$

T4*

$\mathrm{T} 5 * *$

$\mathrm{T} 6 * * *$

\section{Descrição dos tratamentos}

Uso dos valores ETo apenas preditos, utilizando série histórica de dados

Uso dos valores ETo apenas preditos ao longo do experimento

Uso dos valores ETo estimados segundo valores diários de ECA

* - Valores de ETo (evapotranspiração de referência) estimados segundo o método de Penman-Monteith (Allen et al., 1998).

** - Valores de ETo estimados diariamente com base nos valores de E (evaporação) do tanque Classe A (Doorenbos \& Pruitt, 1976).

*** - Irrigações feitas quando as leituras de tensiômetros, a $20 \mathrm{~cm}$ de profundidade, no solo, indicavam de 60 a $70 \mathrm{kPa}$ 
Em todos os tratamentos, as lâminas de água aplicadas foram estimadas para elevar o teor de umidade do solo, até $40 \mathrm{~cm}$ de profundidade, ao valor correspondente a 10 $\mathrm{kPa}$ (capacidade de campo). As irrigações foram realizadas utilizando-se quatro aspersores setoriais, instalados nos cantos de cada parcela de $12 \mathrm{~m} \times 12 \mathrm{~m}$, previamente calibrados, e o volume de água aplicada em cada parcela foi determinado como a média do volume coletado em quatro coletores instalados no centro de cada parcela, distanciados $4 \mathrm{~m}$ entre si. Os dados fenológicos do milho, bem como da colheita, foram obtidos no interior da parcela, de uma área útil de $7 \mathrm{~m} \times 7 \mathrm{~m}$. A coleta de plantas para determinação da matéria seca total foi feita em $1,0 \mathrm{~m}, 0,6 \mathrm{~m}$ e $0,5 \mathrm{~m}$ da linha de plantio, semanalmente. A colheita foi feita em $03 / 07 / 2003$ e 22/01/2004, para os experimentos de janeiro e setembro, respectivamente, utilizando-se várias fileiras da área útil, totalizando $20 \mathrm{~m}$ de linha.

\section{Resultados e Discussão}

As Figuras 1 e 2 mostram os valores de ETo, estimados segundo três estratégias utilizadas, nos tratamentos T1, T2 e T4.

Observa-se, nas Figuras 1 e 2, que os valores de ETo do tratamento T1 superam os valores de ETo do tratamento T2, estimados pela média. Por outro lado, é possível observar a grande variabilidade dos valores de ETo diários, no tratamento T4, calculados diariamente. No plantio de janeiro (Figura 1), as curvas de ETo ajustada e predita e ETo média vão se aproximando cada vez mais, do plantio até a colheita em julho, em consequência da redução dos dias chuvosos da série histórica, e, conseqüentemente, menos ajustes dos dados foram necessários com o passar do tempo. A mesma tendência, mas de forma inversa, ocorreu no plantio de setembro, em que as curvas estavam próximas, por ocasião do plantio, e se afastaram com o tempo, até a colheita, devido ao aumento de dias chuvosos na série histórica, para se efetuarem os ajustes.

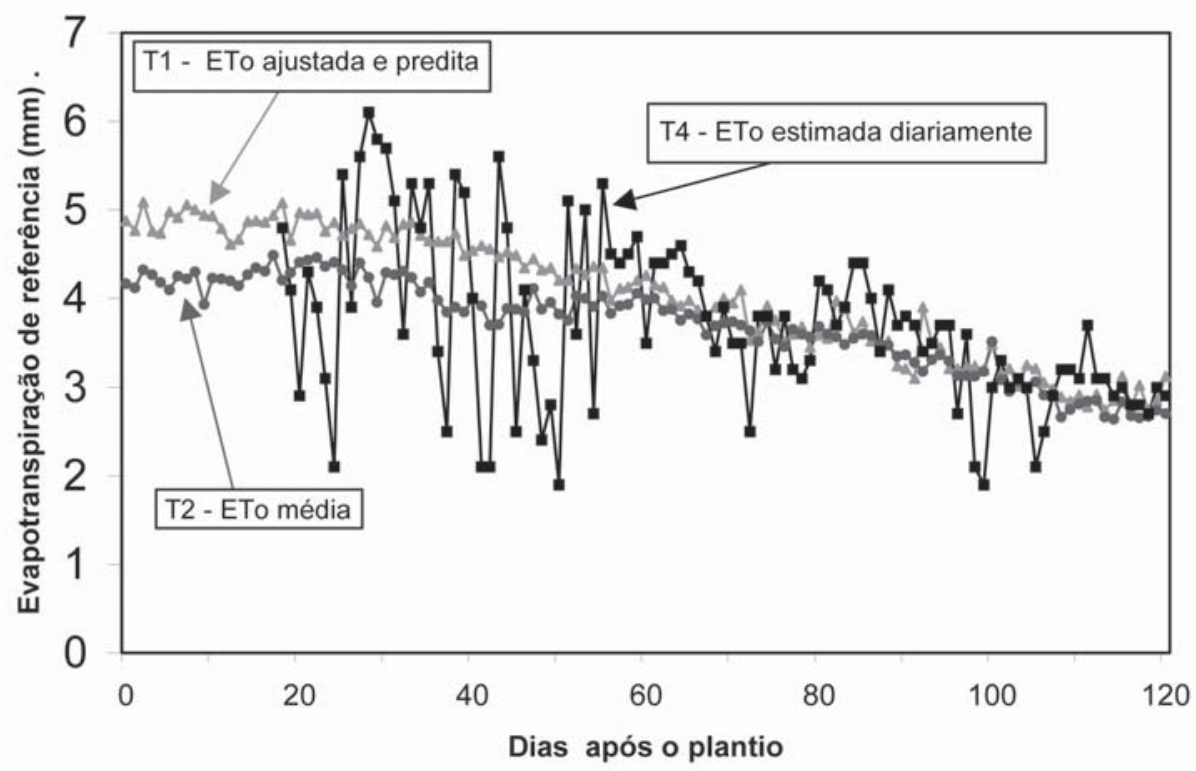

FIGURA 1. Comparação de dados de evapotranspiração de referência (ETo), dos tratamentos T1, T2 e T4, durante o ciclo do milho, no plantio de janeiro 
As Figuras 3 e 4 mostram a evolução do acúmulo de matéria seca na palha e na espiga ao longo do ciclo da cultura, no plantio em setembro. É possível observar que houve uma tendência de os tratamentos T4 e T1 apresentarem maiores valores de matéria seca, tanto da palha quanto da espiga, a partir do terço superior do ciclo da cultura, enquanto o tratamento $\mathrm{T} 2$ apresentou menores valores.

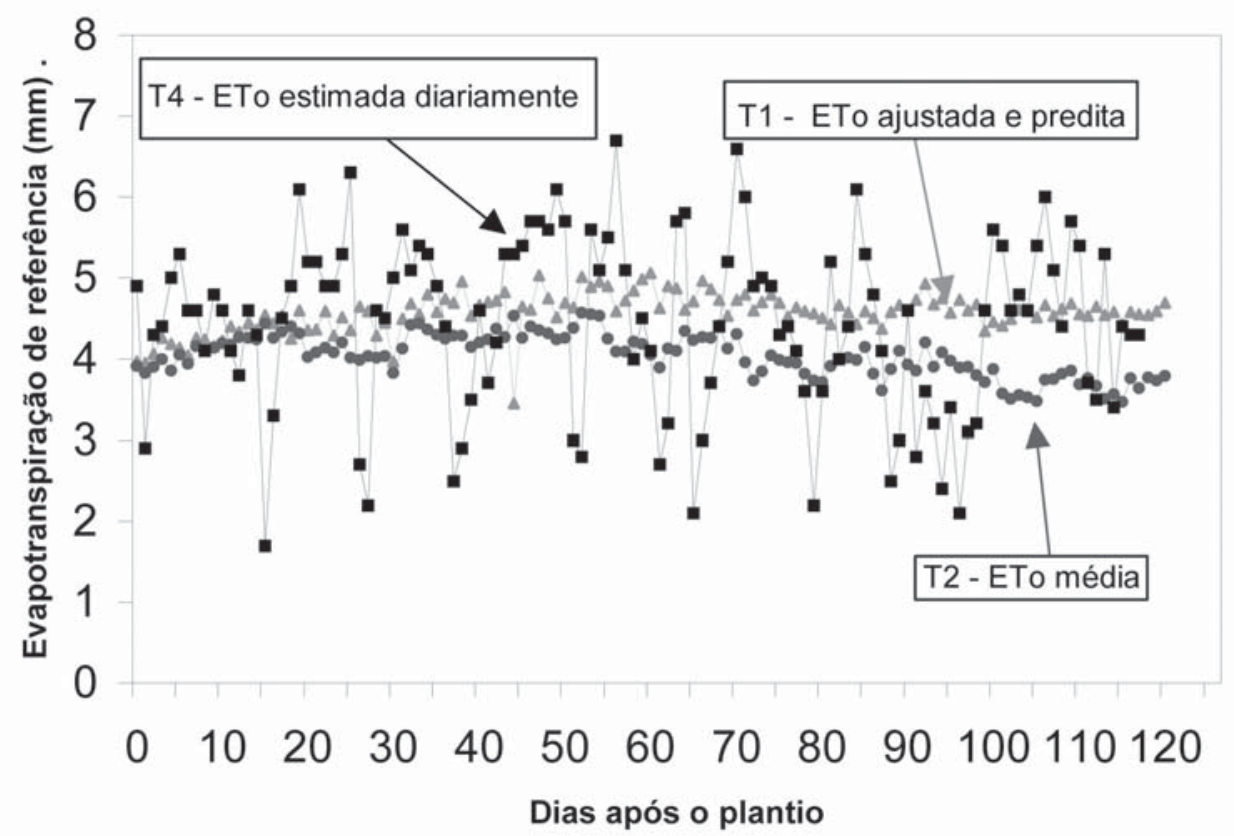

FIGURA 2. Comparação de dados de evapotranspiração de referência (ETo), dos tratamentos T1, T2 e T4, durante o ciclo do milho, no plantio de setembro.

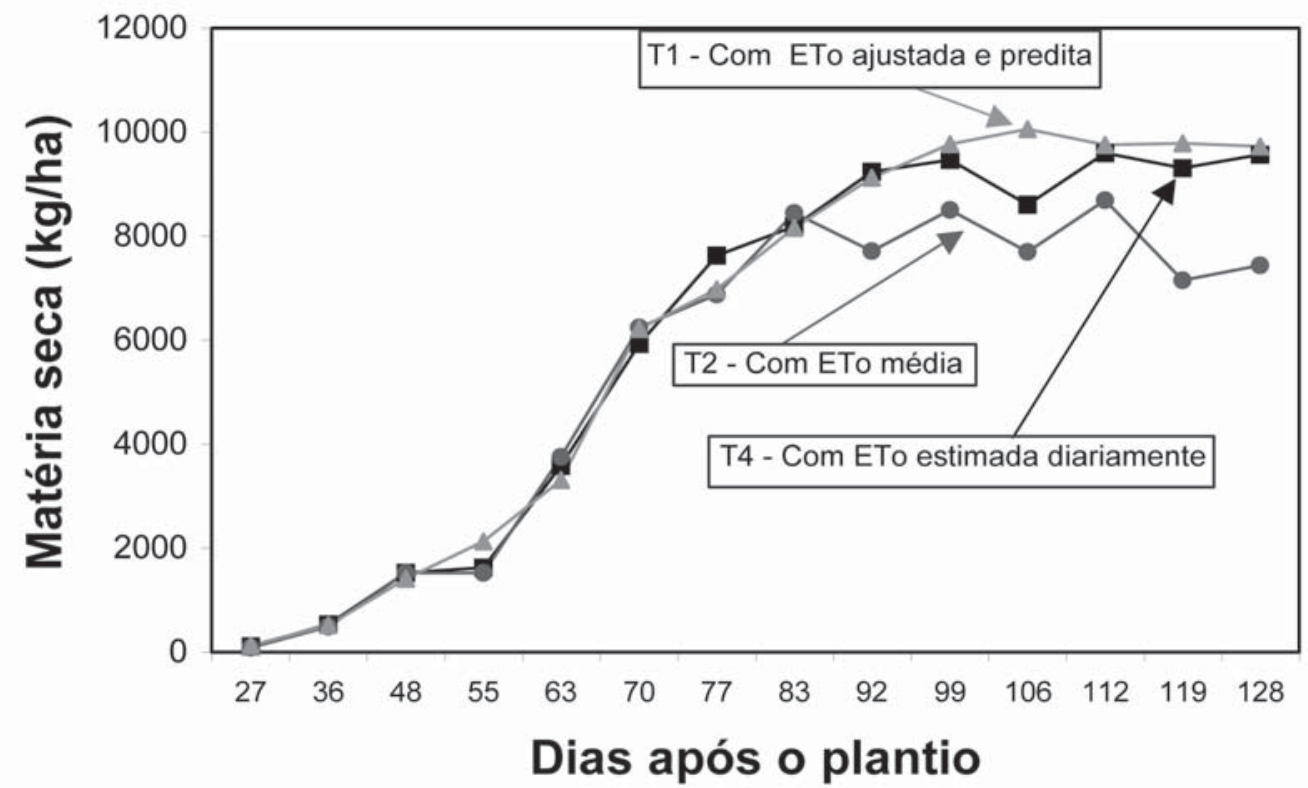

FIGURA 3. Acúmulo de matéria seca na palha de milho ao longo do ciclo, nos tratamentos T1, T2, e T4, no plantio de setembro 


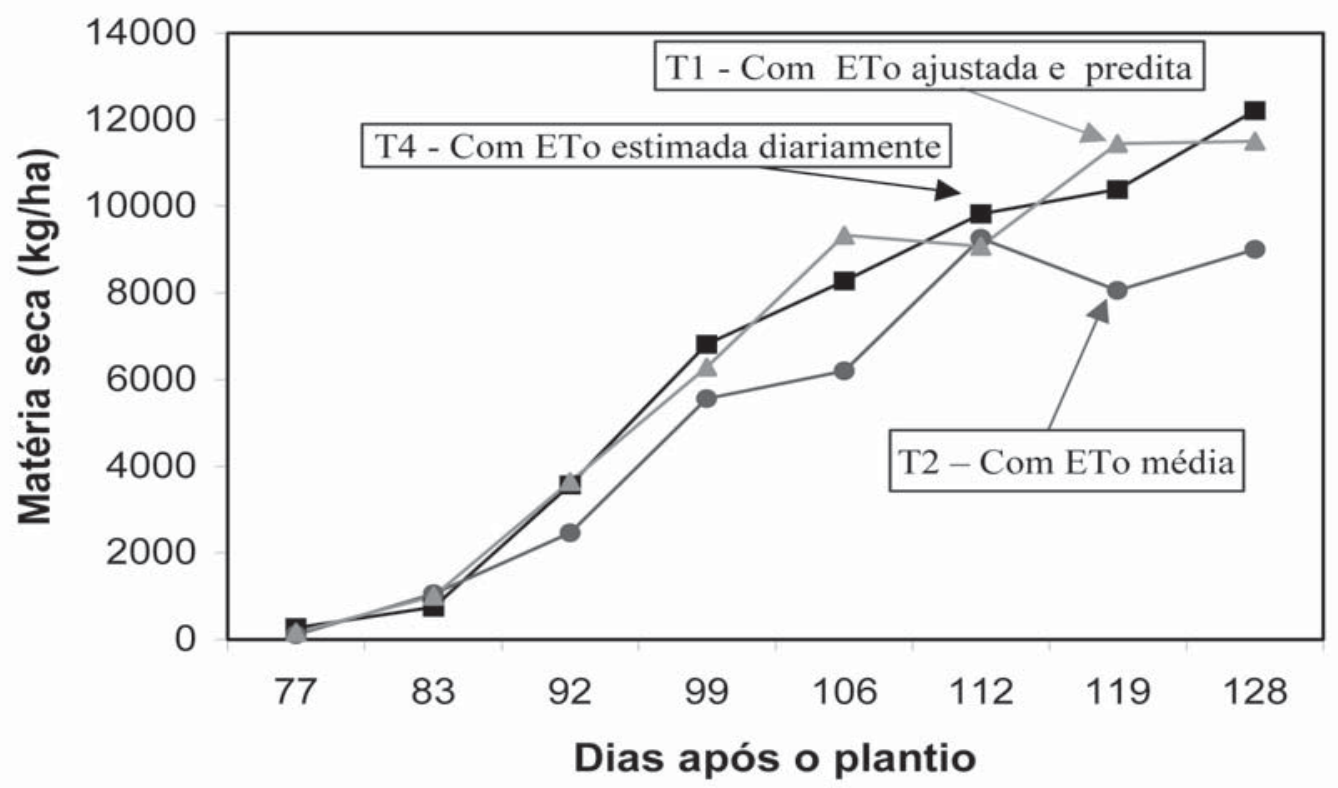

FIGURA 4. Acúmulo de matéria seca na espiga de milho ao longo do ciclo, nos tratamentos T1, T2 e T4, no plantio de setembro

O comportamento do acúmulo de ma- nas irrigações, bem como do número de irritéria seca nos diversos tratamentos segue a gações realizadas em cada tratamento (Tabemesma tendência do total de água aplicado la 3).

TABELA 3. Produção média de grãos de milho $\left(\mathrm{kg} \mathrm{ha}^{-1}\right)$, total de água aplicado $(\mathrm{mm})$ e número de irrigações, em cada tratamento.

\begin{tabular}{llccccc}
\hline & \multicolumn{3}{c}{ Plantio de janeiro } & \multicolumn{3}{c}{ Plantio de setembro } \\
\cline { 2 - 7 } \multicolumn{1}{c}{ Tratamentos } & $\begin{array}{c}\text { Produção } \\
\text { de grãos } \\
\text { (kg/ha) }\end{array}$ & $\begin{array}{c}\text { Água } \\
\text { aplicada } \\
\text { (mm) }\end{array}$ & $\begin{array}{c}\text { Número } \\
\text { de } \\
\text { irrigaç̃̃es } \\
\text { feitas }\end{array}$ & $\begin{array}{c}\text { Produção } \\
\text { de grãos } \\
\text { (kg/ha) }\end{array}$ & $\begin{array}{c}\text { Água } \\
\text { aplicada } \\
\text { (mm) }\end{array}$ & $\begin{array}{c}\text { Número } \\
\text { de } \\
\text { irrigaçóes } \\
\text { feitas }\end{array}$ \\
\hline T4 - Uso de ETo** apenas predita & $5688,9{ }^{*}$ & 232,1 & 6 & $7026,7 \mathrm{ab}$ & 180,9 & 5 \\
T1 - Uso de ETo ajustada e predita & $5612,7 \mathrm{ab}$ & 245,9 & 7 & $7194,0 \mathrm{a}$ & 167,4 & 5 \\
T6 - Uso de tensiômetros & $5561,7 \mathrm{ab}$ & 232,3 & 6 & $6037,7 \mathrm{c}$ & 73,9 & 2 \\
T5 - Uso de ETo estimados & $5272,9 \mathrm{ab}$ & 229,1 & 7 & $6830,0 \mathrm{ab}$ & 176,5 & 5 \\
segundo valores diários de ECA & & & & & & \\
T2 - Uso de ETo média & $4801,6 \mathrm{bc}$ & 178,2 & 5 & $6485,0 \mathrm{abc}$ & 121,4 & 3 \\
T3 - Uso de ETo apenas predita & $4259,3 \mathrm{c}$ & 205,1 & 5 & $6266,7 \mathrm{bc}$ & 125,5 & 3 \\
C.V. (\%) & 8,76 & & & 6,31 & & \\
\hline
\end{tabular}

* Médias seguidas da mesma letra não se diferem significativamente, ao nível de 5\%, pelo teste LSD (least significant difference)

** Evapotranspiração de referência 
A Tabela 3 apresenta as produções médias de grãos para os tratamentos relativos aos experimentos, com plantios em janeiro e setembro. Neste trabalho, o tratamento T4 foi considerado como referência, uma vez que o método de balanço de água no solo, usando-se a Eto, calculada diariamente pelo método de PenmanMonteith, é considerado o mais preciso. Observa-se que o T4 foi o primeiro e o segundo mais produtivo nos experimentos de janeiro e setembro, respectivamente, não diferindo estatisticamente dos tratamentos T1 e T5, em ambos os plantios. Observa-se, também, que os tratamentos T2 e T3 não diferiram estatisticamente, entre si, em ambos os plantios. Ambos obtiveram menores produtividades do que o tratamento $\mathrm{T} 4$, no plantio de janeiro, e menores que o $\mathrm{T} 1$, no plantio de setembro.

$\mathrm{O}$ aumento do número de irrigações, bem como da lâmina total de água aplicada, em cada tratamento, tendeu a se relacionar com o aumento da produtividade de grãos dos respectivos tratamentos (Tabela 3 ). Esses resultados indicam que a programação de irrigação pelo método do balanço de água no solo, utilizandose a média da ETo (T2) ou a predição da ETo, utilizando RNAs de uma série de dados climáticos (T3), afetou negativamente a produtividade do milho, quando comparado com o uso da ETo estimada diariamente pelo método de Penman-Monteith, (T4), pelo uso da evaporação de água do tanque classe A (T5) ou pelos dados de ETo ajustados e preditos (T1), segundo metodologia de Resende et al. (2002). Resultados semelhantes foram conseguidos por Resende et al. (2003), em trabalho de simulação, utilizando as estimativas de ETo, conforme feito para os tratamentos T1, T2, T3 e T4, para cinco épocas de plantio, por ano, durante 12 anos, para as condições de Sete Lagoas, MG.
Observa-se pelos dados de produtividade apresentados na Tabela 3, que o tratamento T6 não diferiu estatisticamente do T4 no plantio de janeiro; no entanto, foi o que apresentou a menor produtividade no plantio de setembro. Esse resultado pode ter sido devido à troca das rolhas de origem francesa por rolhas nacionais, nos tensímetros, o que pode ter permitido a entrada de ar pelos orifícios da agulha, acusando tensões de água no solo inferiores às que realmente ocorriam.

\section{Conclusões}

O manejo das irrigações pelo balanço de água no solo, utilizando a ETo estimada diariamente pelo método de Penman-Monteith, considerado como padrão, e utilizando valores de ETo ajustados e preditos por Redes Neurais Artificiais, com base em uma série histórica de dados climáticos de 45 anos, proporcionou as maiores produtividades de milho, nos plantios de setembro e janeiro, nas condições de Sete Lagoas, MG.

O manejo das irrigações pelo balanço de água no solo, utilizando valores médios de ETo calculados pelo método de Penman-Monteith, de uma série histórica de dados climáticos de 45 anos, determinou redução de produtividade de milho no plantio de janeiro, em relação ao uso de ETo estimada diariamente pelo método de Penman-Monteith, nas condições de Sete Lagoas, MG. Houve tendência semelhante no plantio de setembro.

O método do balanço de água no solo, utilizando valores de ETo preditos e não ajustados previamente por Redes Neurais Artificiais, determinou redução de produtividade de milho no plantio de janeiro, em relação ao uso de ETo estimada diariamente pelo método de PenmanMonteith, nas condições de Sete Lagoas, MG. 
Houve tendência semelhante no plantio de setembro

O uso dos valores de ETo diários, ajustados e preditos por Redes Neurais Artificiais, usando-se ETo estimada através de dados climáticos de uma série histórica, além de ser de fácil obtenção, permite estabelecer um calendário das irrigações antes mesmo do plantio, com a mesma precisão do uso de ETo estimada diariamente pelo método de Penman-Monteith.

\section{Literatura Citada}

ALLEN, R. G.; PEREIRA, L. S.; RAES, D.; SMITH, M. Crop evapotranspiration: guidelines for computing crop water requirements. Rome: FAO, 1998. 300 p. (FAO. Irrigation and Drainage Paper, 56).

ALMEIDA, F. T. Avaliação dos sistemas de irrigação pressurizados e do manejo da água na cultura da banana no Projeto Gorutuba. 1997. 100 f. Tese (Mestrado) - Universidade Federal de Viçosa, Viçosa.

CEMIG. Estudo de otimização energética em irrigação por aspersão convencional. Relatório final Belo Horizonte, 1996. 26 p.

CEMIG. Estudo de otimização energética: setor irrigação - pivô central. Belo Horizonte, 1993. $22 \mathrm{p}$.

CHRISTOFIDIS, D. Recursos hídricos e irrigação no Brasil. Brasília: Universidade Federal de Brasília; Centro de Desenvolvimento Sustentável, 1999. 34 p.

DOORENBOS, J.; PRUITT, W. O. Crop water requirements. Roma: FAO, 1976. 194 p.

JENSEN, M. E.; BURMAN, R. D.; ALLEN, R. G. Evapotranspiration and irrigation water requirements. New York: ASCE,
(ASCE -Manual and Report on Engineering Practice, 70).

KUMAR, M.; RAGHUWANSHI, N. S.; SINGH, R.; WALlENDER, W. W.; PRUITT, W. O. Estimating evapotranspiration using artificial neural network. Journal of Irrigation and Drainage Engineering, New York, v. 128, n. 4, p. 224-233, 2002.

RESENDE, M. Metodologia para corrigir, predizer e disponibilizar a evapotranspiração de referência, através de redes neurais artificiais, para racionalização de práticas de manejo de irrigação. In: CONGRESSO NACIONAL DE MILHO E SORGO, 23., 2000, Uberlândia. A inovação tecnológica e a competividade no contexto dos mercados globalizados: resumos. Sete Lagoas: ABMS, Embrapa Milho e Sorgo, Universidade Federal de Uberlândia, 2000. p. 120.

RESENDE, M.; SOUZA, L. M.; CAMINHAS, W. M.; PATARO, C. D. M. e FARIA, C. M. Utilização de redes neurais artificiais na correção e predição da evapotranspiração para programação de irrigação. In: CONGRESSO NACIONAL DE IRRIGAÇÃO E DRENAGEM, 12., 2002, Uberlândia. Anais... Uberlândia: ABID, 2002. CD-ROM.

RESENDE, M.; COUTO, L.; ALBUQUERQUE, P. E. P. Manejo de irrigação. In: RESENDE, M.; ALBUQUERQUE, P. E. P.; COUTO, L. (Ed. ). A cultura do milho irrigado. Brasília, DF: Embrapa Informação Tecnológica, 2003. cap. 5, p. 265-301.

RESENDE, M. Método Resende: uma estratégia simples e precisa para se programar irrigação. In: CONGRESSO NACIONAL DE MILHO E SORGO,25., SIMPÓSIO BRASILEIRO SOBRE A LAGARTA-DO-CARTUCHO, 
SPODOPTERA FRUGIPERDA,1., 2004, Cuiabá. Da agricultura familiar ao agronegócio: tecnologia, competitividade e sustentabilidade: [resumos expandidos]. Sete Lagoas: ABMS, Embrapa Milho e Sorgo, Empaer, 2004. CD-ROM. Seção Palestras.

SMITH, R. C. G.; STEINER, W. S.; MEYER, W. S.; ERSKINE, D. Influence of season to season variability in weather on irrigation scheduling of wheat: a simulation study . Irrigation Science, Berlin, v. 6, p. 241-251, 1985 .
SOUZA, L. M.; FARIA, C. M.; PATARO, C. D. M.; RESENDE, M.; CAMINHAS, W.M. Desenvolvimento de metodologia para ajuste e predição de taxa de evapotranspiração utilizando redes neurais artificiais. In: CONGRESSO NACIONAL DE IRRIGAÇÃO E DRENAGEM, 12., 2002, Uberlândia. Anais... Uberlândia: ABID, 2002. CD-ROM.

STEELE, D. D.; STEGMAN, E. C.; KNIGHTON, R. E. Irrigation management for corn in the northern Great Plains, USA. Irrigation Science, Berlin, v. 19, p. 107-114, 2000. 